\title{
The Hospital School towards an Integrated Model of Training of Quality
}

\author{
Ferrara Lydia ${ }^{1}$, Flammia Aurora ${ }^{2, *}$ \\ ${ }^{1}$ Department of Pharmacy, University of Naples “Federico II” via Domenico Montesano, Naples, Italy \\ ${ }^{2}$ ISFOM, Istituto Formazione Musicoterapia, corso Vittorio Emanuele, Naples, Italy \\ *Corresponding author: aurora.flammia@virgilio.it
}

Received November 06, 2013; Revised November 27, 2013; Accepted December 04, 2013

\begin{abstract}
The organization of the education service in hospitals expresses the recognition of the fundamental right to education and the advancement of a culture of solidarity in favor of children and young patients in situations of temporary disadvantage. The Hospital School, in the context of a logic of inter- institutional agreement between the Ministry of Education, Ministry of Health and Ministry of Social Affairs, currently, it is increasingly transformed into a school structure organized as part of the offer training provided for, in terms of organizational and didactic autonomy. In fact, to ensure the full exercise of the right to education, in addition to educational activities, in accordance with the particular experience of hospitalized children, it helps to overcome the trauma of hospitalization with appropriate educational support, ensuring the continuity of contact with their school of origin.. Sending a teacher at home if the disease prevents school attendance also promotes reintegration after discharge with supplementary educational programming interventions with teachers, hospital workers, family, operators of recreational activities - agers and volunteering. In view of the characteristics of the condition of his pupils, the school is placed in the hospital that aims original and innovative, thanks to the technological support, allow optimal interaction between therapeutic and educational project.
\end{abstract}

Keywords: hospital school, Education Homecare, integrated model

Cite This Article: Ferrara Lydia, and Flammia Aurora, "The Hospital School towards an Integrated Model of Training of Quality.” American Journal of Educational Research 1, no. 10 (2013): 442-448. doi: 10.12691/education1-10-6.

\section{Introduction}

The school, from the earliest years of age, is the place where the child begins to build its identity, because for the first time moves away from parental figures and is called to manage relationships and dynamics independently. The school therefore has to be implemented not only as a duty to be performed, but also as a right that is offered for personal training.

To protect and combine the two constitutionally guaranteed rights, the right to health and to education, aimed at a range of students in difficulty, the training provided by the school in the hospital is very unique, with regard to the recipients, pupils hospitalized, and the method of payment. Born from experience episodic based on the availability and willingness of individual actors and institutions, over time it became a service with its own identity, easily recognizable and truly integrated. Today, the presence of the hospital school no longer has the exceptional nature, it is now a well established not comparable to other forms of animation and entertainment, as it is not a breakthrough moment in the school system, but is now an institutional reality in our country and presents itself as a permanent service aimed at students who are forced for a long time in a hospital bed.
"Often children with chronic illnesses or who suffer significant and/or repeated hospital admissions, if they are not properly secured in the field of education and instruction, come to an early drop-out, but even more to a cultural level so low compared to that of peers and so inadequate to the demands of today's society as to make individuals at risk psychosocial issues, especially with regard to their integration into the labor market, resulting in a high social cost" [1].

The educational intervention is designed to ensure equal opportunities for pupils admitted, enabling them, where possible, to continue the development of skills and competencies and ranks within the broader framework of actions to prevent and combat early school leaving and to facilitate reintegration into the school context of origin. The educational and organizational flexibility, in fact, valid for the whole school, is modulated in an original and innovative in this area, particularly in terms of technology. The function of the teacher in the hospital also appears to be important because, in addition to ensuring a "bridge" between the family and the hospital, also has the delicate task of promoting the right to education in a context so delicate and complex.

Today, training is widespread in all types and grades of school and in leading hospitals and pediatric wards of the national territory, adapting to changes in the health system and responding flexibly to the needs of day-care and 
education home care. The hospital school has relatively recent origins in Italian as can be seen by a ministerial circular of 1936 which authorized the Italian Association of Educators (AEI ) to investigate the need of hospitals to hire teachers within their workforce. The war, however, restrained every legislative intent and its aftermath have had to address issues of higher priority. You will have to wait 50s years of the dissemination of research humanization of health facilities and years of profound social change, to see that public institutions are progressively replace, in hospital management of school activities, volunteer work. Were the first open sections of special schools in some pediatric wards which, with the help of primary school teachers, they were able to provide instructional support to young patients to avoid the difficulties typical of the return class of origin [2]. Then the hospitalizations were long, and the considerable difficulties encountered by the child in recovering the program and catch up with the others. Although hospitals and pediatric wards in subsequent periods will be transformed with a view to make the stay more enjoyable for children, legislative gaps will persist for much longer, until the nineties, when it increases the interest in these issues by the scientific community, public opinion and institutions. It is from that moment began to multiply the school sections in pediatric hospitals, with the aim not only to ensure that students' educational assistance, but also to provide the proper support to the psychological and emotional distress arising from the disease.

The Ministerial Circular (CM) of 1986, 2 December, n. 345 ratifies the birth of the school sections in hospitals. With it and with subsequent work is formulated in the normal school in hospital as a branch of the school in the area. The subsequent C.M. of 1998 n. 353 claims that "organizing the hospital school is to recognize the young patients the right/duty to education and help to prevent early school leaving and abandonment”. This document aims to turn the school into a real hospital education service and not just a set of sporadic interventions that are based on intuition. There are then two memoranda of understanding, one in 2000 on "Protection of the rights to health, play, education and maintenance of emotional relationships and friendship of the citizens of minors sick" and the other in 2001 that emphasize the importance of playful dimension to be preserved even in the hospital setting and for the first time recognize the child also social needs, such as maintaining the ties of friendship prior to admission. We therefore want to encourage all those occasions in which the young patients can become consumers of cultural and artistic events, even within the hospital, thus experiencing, in addition to situations out of the daily routine, even irreplaceable formative moments for their strong emotional valence.

\subsection{Inizio Modulo}

In the subsequent C.M. 43/01 reiterates that service learning has become an integral part of the healing process, not only because it responds to a law expressed by our Constitution, but also to ensure the maintenance of the psychophysical situation in the child's hospitalization. The document also clarifies the relations which should exist between school and hospital school of origin, highlighting all those tasks that compete for the second, but which are frequently delegated to others. There are two other ministerial circulars on the subject (the CM 56/ 03 CM and 108/ 07) which again emphasize the peculiar features of the teacher hospital, also relatively new to home education perspective, also be considered a true and its education service. In recent years, in fact, the focus has shifted more and more towards this new form of education, because the shelters are becoming shorter, but once you leave the hospital sick children are forced to stay at home for the convalescence period and for those who must stay for a period longer than one month was provided for home education, which is proposed with personalized interventions to continue their studies and to reduce the isolation of the patient. This service is an extension of the training of the Hospital School, recognizing the sick children - where necessary - the right / duty to education even at home. With the reduction of periods of hospitalization, followed the approval of the Health Plan 2002-2004, today, even in severe cases, we tend to send home the child or the boy, continuing to follow in daycare for all period of care. In these cases, following the approval of a specific project, the minor is unable to attend school for at least 30 days can be followed at home by one or more teachers.

Although it is not possible to program in a systematic intervention year, due to the inability to predict the user, the service must be based on organizational flexibility, which allows to adapt what has been designed to a specific context. You cannot make reference to the typical class, since such a subdivision would be too rigid in hospital, where not ensure a stability of pupils: the best operating mode to be adopted is that of creating a small group. We then invite the teachers to maintain contact with hospital institutions of provenance and to update on the operation of new technologies, which are essential to enable young patients to keep in touch with old comrades. Teaching electronically will be even more necessary than in the traditional school, because in this case the employees belong to areas completely unrelated to that of education. Health professionals have certainly different skills, but they are essential in providing information about the child and in order to understand how best to act with the individual pupil; cooperation is also needed even with those who are concerned with leisure and recreational activities, carrying out Community projects involving all the patients.

The operation of the hospital school requires a scheduled report and agreed with the health and social services for assistance equivalent ASL and local authorities. They are then locally agreed ways of strengthening the training of teachers on the disciplines of e on defined projects of home education.

Complementing the services of Hospital School and Education Homecare we organize training interventions at multiple levels, aimed at both the teaching staff to the administrative, designed to provide adequate training to employees participating in the activities (in many respects extraordinary) School in hospital, they aim to optimize the specific preparation than the typical critical contexts in question, thus constantly improving the service provided to the end user.

\section{Objectives}


"The main purpose of the hospital school is to keep alive and vibrant identity of the child, in an anonymous and impersonal environment and in an environment full of anxieties and fears which is that of disease" [3]. The operation of the school sections hospital has the primary characteristic mode of service delivery, which takes into account both the physical condition of the person as of the psychological ones. Next to the pain of the disease, there is the fear of losing a year. For the child in the hospital is important to the continuity of his course of study: in his micro hospital environment must not only learn, it must also do not feel isolated from his teammates and at the same time find opportunities to socialize and commitment. And essential to the presence of specialized teachers, accustomed to living the hospital environment, which can deal with the didactic and that, together with the parents, can make more bearable the child to remain in an environment so "special". The visit school teacher and classmates will help the child to overcome this difficult time.

The hospital school experiences and constantly puts into practice the "integrated model of intervention" in which have been identified mode of connection between the pre-schools, primary and secondary reality that may be present in the same hospital, representing a concrete example of how subjects, school staff and health services and institutions, each with their own objectives, may, in contexts such sensitive or critical, not only to meet but also interact positively to the development of interventions united by the same purpose, namely, to promote wellbeing and personal growth.

When a child enters the hospital feels deprived of everything that belonged to him, he feels far away from the people with whom he interacted often, is forced to live in an environment that does not know, in close contact with strangers, and it is to these strangers that he must entrust his life. The hospital, in fact, as a humanised environment is physiologically less adequate to accept the child, however, is prepared for the outdoors, for playful situations, to actually pleasant. First, it is therefore necessary to minimize the possibility that the child goes to the hospital, creating a network of family doctors and specialists of childhood illnesses that allows home care and, if possible, prevention of the disease. If the hospital is necessary, should be shortened as much as possible the same time of admission, it must then make the hospital suitable for children, harmonizing the times, the visits, the building and in particular the environment with colors, furniture, photographs and objects familiar to him. This is why the Italian pediatrie are turning into the most comfortable and less formal, where you rethink the spaces not only in terms of functional logic, but also in the small patients. Are set up game rooms, favored cultural initiatives play and recreation, repainted and decorated the halls, set up small libraries, as well as promoted shows for pupils and families.

The service of home education, which continues to grow year on year in all the areas and regardless of the presence of pediatric health care facilities, is characterized as a particular mode of exercise of the right to education, that every school must be able and know how to offered in case of documented request from the parents, while respecting the prerogatives of contractual teachers. As such, it must be provided within the Plan of Studies of each school. Parents submit a request to the school where the pupil is registered, accompanied by a medical certificate issued by the doctor at the hospital where the student has been admitted, the school concerned shall prepare a draft training offer the pupil is unable to attend school, with an indication of its duration, the number of teachers involved and declared themselves available and the lessons planned, the project is approved by the faculty and the board of the Institute and included in the POT (Plain Offers Training), the request with attached health certification and the project developed, it is then forwarded to the appropriate Regional Education Office (EOR) which shall assess the documentation submitted for approval and subsequent allocation of financial resources as a result of regional clearance can starting the business from home schooling.

The home education may be granted only where the serious illness that act does not provide for the hospitalization but prevents the same time, the frequency of school for a long period of time, not less than 30 days. The time period, in any case not less than 30 days, may be not continuous only in case of hospital care are planned cycles alternating cycles of home care. The pathology and the period of impediment to school attendance will be subject to appropriate health certification.

The growing increase in requests for home education throughout the country, as can be seen from the data of the annual monitoring, brings out strongly the need for frequent training of teaching staff and manager who, for the first time faces to this form of training offered at home, on a variety of topics such as how to deliver the service, the count of absences for the validity of the school year and the assessment of students who have followed a "irregular path".

In the perspective of the establishment of a real treatment team, doctors, nurses, teachers, educators, psychologists and volunteers should feel part of the same plan of care; objectives will have to be common and the means to execute them will be different should never obstruct each other as there 's most important intervention, except in cases of emergency, and the centrality of the child should always be considered.

\subsection{Inizio Modulo}

It is a truly integrated territorial development through consultation between the parties involved and responsible, a real network and shared it possible to respond to the global needs of the subject in training and above all offer quality, integrating services and expertise.

For example, design a Facebook group to recreate the class in a virtual environment and Skype allows teachers to organize lessons, live from the computer lab in the creative, allows you to keep the balance personal and informal contact with peers also time out of school. Today, new technologies mean that the achievement of this goal will be realized more easily, allowing a direct exchange between teachers who can agree on a common program and personalized for each resident, which in turn can communicate with their classmates and with the teacher simultaneously.

Finding a place in the hospital of "normality" is for the sick little reassurance that prepares him to return to his old life, she looks to its future, worrying about his well-being 
in a place where the focus of everyone's attention is instead the pathology. Studying in the hospital does not mean to burden the resident of a tedious weight forcing him to follow the curriculum, but it means to stimulate the child's potential in respect of his illness and emotional experiences related to it. In order to promote the dissemination of the culture of the hospital school, you will need to improve the professional skills carryforwards, create new channels targeted training to the acquisition of specific skills, build a network among stakeholders, encourage integrated working methods for the optimization between therapeutic and educational project.

The hospital school is now well established in our country and also the legislation is becoming more and more attentive to the changing needs of the industry. Unfortunately, there are still problems, first of all concerning the upper secondary level: it is difficult to provide a service of this kind is for the variable number of students admitted to this age group, and for the wide variety of addresses of our institutions upper [4]. Usually it tries to ensure the basic subjects and resorting to occasional services to those that characterize it. The overall picture, however, is very heterogeneous and also the ongoing trials in this regard are scarce.

\section{Methods}

The reality of schools in hospitals in Italy is very different, because the policy of hospitals differs from region to region, and even from province to province, in relation to the diversity of the catchment area, it is clear that a general hospital can not offer the same services for children in a pediatric clinic. Also contribute to this disparity also the economic resources available to be used taking into account especially health emergencies.

In Italy there are the experiences of hospital school, especially primary, thirty-year, as in the cases of the Infant Jesus of Rome and the Gaslini Institute of Genoa. In these contexts, the teachers who coordinate the teaching are numerous and in recent years have increased exchanges with other educational services hospital. The pupils of the Gaslini have contributed to the creation of the interactive game "Florindo" and realize the on-line magazine "A blast from the network". In this hospital also teachers at the various school levels wearing a coat of a different color to stand out in the eyes of the young patients.

The situation of the school of the second degree, even in these most advanced companies have a precarious nature: is offered only upon request through the permanent collaboration of one or more teachers of a school campus citizen, just to meet the diverse needs of patients. The tele - class [5] has been successfully tested in several hospitals and also the publication of material on the web is quite common because the computer has become an indispensable resource because it allows you to communicate with the outside world through a language familiar to even the smallest.

In Piemonte, a good job network has allowed us to create a Technical Working Group to coordinate all regional initiatives in this area: a site collects all the experiences underway in the region, and has been published an information guide, as well as illustrating the situation of Piedmont, did understand the peculiar value that the school takes in a similar context.
In Parma have been implemented two very significant: The hospital I know him too, addressed to children of nursery and articulated around the story of Tilly, a special butterfly and the project CASPER, with the aim of making known "the hospital" to pupils in all its different aspects, not only doctors, but also entertaining and educational, asking sick children to express their perception of the hospital. Is also introduced "We know the hospital", a path of health education implemented in Florence for children of compulsory education, which, in addition to several "lessons" on the issue, even the screening of the movie The teddy bear Judy is hospitalized and a guided tour at the Meyer Children's Hospital [6]. Just at this institute is achieved through a magazine, "I am sending you a nice hello", which involves the collaboration of hospitalized children and pupils from the nearby elementary school, working on a common theme annually and write their comments on the subject. In the Infant Jesus of Rome, there is a similar initiative: the magazine "Guys, Stories and Fantasy...”, prepared twice a year by the patients, who have the opportunity to attend a workshop of reading and writing. Parents are also involved lab- support "Listen who's talking...” where they can intervene with letters and comments.

The most interesting aspect is the collaboration between Kites in the pajamas of the Infant Jesus with the Red fishes of Palidoro, the Swallows manzoniane of Catanzaro and Fantafolletti of Turin: the matching of hospitalized children are pupils of the elementary school classes in various Italian cities that through the project Edelweiss communicate in a telematics and share with their daily experiences, tours, stories and nursery rhymes. Edelweiss is a project initiated in 1997, with the support of Italy under the Hewlett Packard HP- Europe philanthropic program, aims to explore the potential of information and communication technologies in support of the hospital school. It is based on close co- ETI (Institute for Educational Technology ) with the Board of Education of Genova Sturla, The Children's Hospital “Gaslini” Institute Elis in Rome and several other schools across the national territory, both external and internal hospitals. The priority objectives are to enable children and young people longterm care to establish and maintain connections with the outside world to help them feel part of a working group and allowing them to new and rewarding interpersonal relationships; coordinate experiments and study groups, composed of researchers and teachers inside and outside the hospital, in order to examine a specific theme, design and implement teaching sequences in which young patients have the opportunity to participate in educational activities in collaboration with external classes; raise children's awareness - stakeholders from outside the attention and solidarity with peers who are experiencing a situation of illness or discomfort; explore the use of educational software as an additional teaching support in hospital.

The activities with the children in the hospital are on two complementary levels: the first aimed at creating the conditions so that you maintain contact with the outside world, the second aims to promote the training of young resident through the use of technology to carry out activities curricular and extra-curricular of various types (creation stories of many hands, participation in an online learning community, etc.). The technology takes from time to time the role of information allowing amplifier to 
overcome the problems related to information retrieval within the hospital, through research on the Web, the use of software (encyclopedias multimedia), exchange with children in grades external cognitive amplifier when, in addition to stimulating attention, listening, understanding favors the development of metacognitive skills of planning and problem solving through the use of educational software properly selected to participate in a community network learning, and finally the communication allowing amplifier to maintain relations with the outside world (friends, classmates, relatives) and allowing your child to not only how to bring the reality of suffering that is experiencing.

Radio $K 2$ is the project carried out by the students admitted in Auxologico Piancavallo (VB) that allows you to stay in touch and make their voices heard also from the hospital. Since 2008, the radio section of the Hospital Association of School Ranzoni, involving children between the ages of eleven and fifteen years as authors and protagonists of radio series on the topic, and from 2011 was also born TeleK2, through which the boys propose the television series, whose themes relate to science fiction, history, and even lifestyles.

The purpose of these projects shared between the sick children and pupils in elementary school, is to reduce the one hand, the isolation of the first, letting them know also really different from the school of origin, allowing to meet new friends from seconds to allow the other to become familiar with the hospital and found that children who are forced to live there for a while they're not so sad and desperate. They are true testimonies that have a value much stronger than just a guided tour or an informational interview. In addition, these children can practice not only writing and drawing, but also to use the computer thanks to e-mails exchanged with distant companions.

\section{Results}

The formation of the teaching hospital must be the traditional one, but must take into account the specific realities of health care and all the problems related to it. The teacher who work in these contexts must constantly deal with the disease, which must not be neglected either for practical reasons or for reasons psycho- emotional [2].

In fact he must shape the teaching on the class that has the face, which is not formed from healthy children which follow certain pace of work, but is composed of a variable number of small patients of different ages and backgrounds, with different degrees of schooling, which undergo therapies that can cause drowsiness, loss of concentration and other side effects that should be taken into account by those who are in close contact with them, and therefore it is not always possible to program specific interventions. The teacher can also provide these children an emotional container in which to pour out their anxieties and fears and reprocessed through expressive activities proposed; must be able to propose activities for every situation, bearing in mind the presence of older children and smaller. For this the recreational dimension should always be enhanced and used to convey messages of each type. It must offer creative opportunities through which they can express most hidden feelings for the school to take even a hospital therapeutic essential meaning [7].
The teacher is having to deal with situations that are not typical of the traditional school including the presence of parents, who remained close to his son throughout the day on the ward often accompanying him also in the classroom. Sometimes they are the ones who deny the child access to the hospital school, which unlike the normal one is not mandatory, because they consider the lessons to attend a small resident would mean extra effort. These people probably judge only through fear, which leads them to focus only on the condition of the child and on possible means to cure him. They do not know that the hospital school today takes an important role in the therapeutic process, because of all those considerations already explained according to which it is a hospital for a way to distract, to socialize with other patients, to confess their feelings to a person emotionally detached from what is happening and therefore able to offer help more rational.

Teachers are once again those who have to try to mediate with families to help them understand this renewed importance of the school, which brings its benefits not only the immediate and succeeded in making the boy feel calm and confident, but also for the future, because it enables the resident not to interrupt their schooling. The teacher hospital, finally, also has the task of contacting the sending school pupil to agree with colleagues outside a schedule to follow. Teachers need to adopt a common policy to facilitate the future return of the child in the class. Will continue to communicate to update the ongoing situation and also can design the occasions when the small resident may in turn communicate with their classmates or to attend school, at a distance, in a virtual way. In this way, the insulation of the child in the hospital is broken walls to help maintain ties with old friends, that keep you anchored to life outside the hospital.

Certainly it is difficult to plan meetings in the divisions between the child and their school membership, both for health and hygiene reasons both for logistical reasons. Equally complicated is the programming of theatrical performances or art exhibitions within the department, especially for the lack of funds needed for the implementation of these events. Through the tele- class, however, the small resident has the opportunity to follow the lessons of his teacher in real time and experiments in this direction have yielded positive results.

The main difficulties encountered in the implementation of these projects were essentially economic in nature, as schools must be provided with adequate computers and knowledgeable staff. To this end, targeted by the EU funded programs involving collaboration between hospital schools of different countries, such as the project Klini mentioned Lemineur [8] in his speech at the international conference on hospital school of Castel San Pietro Terme (Bologna). The collaboration between two French schools, one German, one Italian, one Belgian and Luxembourg in this case led to the creation of a website and a magazine that collects drawings and texts of the boys admitted. This type of exchange have a high educational value, since beyond the pure enjoyment given by communicating with their peers who live so far away, it allows children to use foreign languages studied at school.

There is a risk that an abuse of tools to further isolate the child, depriving it of human relationships and the pleasure of being with a person in a real way, but in this 
case the role of the adult is essential to balance the interventions and not end the excessive use of electronic means.

\section{Conclusions}

The student is forced to when a hospital stay is subjected to two distinct and autonomous public services as healthcare and education, belonging to two specific legal claims - derived from constitutional - which are to be secured and protected. On one hand, the right to health and, secondly, the social right to education. Therefore, two separate services, two distinct performance, both, however, be provided within a single structure, that hospital. Consequently, they are contextual, not in principle, but by necessity of organization for the rights of the student find their practical realization.

Once past the idea that the school, within the hospital, is somehow a guest, although appreciate and demanded, the concept that must be acquired by necessity - in the event of hospitalization - the dual service to be rendered must be unitary and contextual, served in the structure where the student is forced to remain temporarily.

In such an institutional vision of the problem, the reorganization of the sector of intervention becomes primarily a political problem to be solved. The resulting formulation of practical proposals regarding the reorganization of the regulatory sector, the teaching organization flexible, a critical function of the exercise of teaching and managerial staff within the hospital, with particular reference to adequate professional qualification and the relative positions of status of each person is.

The teaching hospital has now established over time, despite all the shortcomings and limitations detectable in fact, for which targeted interventions are needed: in the legislation reorganization, there is the need of a general protocol of understanding between administrations, and the need for agreements with individual health facilities, in relation to flexible models of teaching organization to be activated, the need to clarify the respective fields of competence - both the structure of the health education service, the need for a teaching facility that allows flexible programming widely, however, in continuity with the activity of the sending schools, the search of a pedagogic space, as a space of communication, is considered absolutely essential, we deem necessary new models of teaching time, we believe particularly useful investigations aptitude towards the teaching staff, with the definition of specific training courses and guided internship possible, it is considered useful to determine the hospital stay of the teaching staff, are considered particularly suitable forms of specific retraining of personnel in collaboration with the structure health, it is proposed the idea of a rota of teachers, it is seen as equally useful the establishment of a database of voluntary participation is required.

Appear to be necessary educational interventionseducational alternative and compensatory, among them the MIUR project "HSH@Network" (Hospital School Home network) which, thanks to the approval of the CMSI (Committee of Ministers for the Information Society) and with funding from MIT (Ministry of Technological Innovation), not only is functional result in the formation of about three hundred seventy teachers belonging to schools of all levels in the different hospitals over the national territory, but guarantees the boys hospitalized or in home schooling the right to education and health through the use of ICT (Information and Communication Technology).

In particular, the school authority, in collaboration with inter-institutional level with other subjects in the area (especially with the municipal entity) is intended to develop a specific project from which to become "highly" the resources that are mobilized: those between human and professional teachers who are to be counted, for various reasons, they belong to the workforce of the school.

The operating modes that affect the nature of home education are often blended e-learning, that is in part characterized by interventions to address the teachers specially appointed and partly made electronically, by giving the student loan to use a personal computer. In this context, the target was made of the aforementioned technologies, as well as membership of seventy Health Management and Administration hospitals identified at ministerial level for the construction of the hospital in every school of wiring in wired or wireless network.

To the Medical involved should be recognized also the merit of having encouraged the use of existing broadband connections, and, if present, to have shared their installation.

The school is in the hospital and then a really great innovation of the Italian School. The skills of teachers are enhanced because the hospital requires the teacher to question the necessity of the student who is in front. The school does not have to be alone in the mission to be pursued but must be shared with the family and with other organizations, to become a school alive that will break down the barriers.

The Home Education is a service provided in relation to the pupils at state schools and equal, for all levels, from Primary School to Secondary School Second Grade, which already hospitalized due to serious diseases, undergo therapies or home health services that prevent school attendance for a period of time equal to or greater than 30 days. The clinical condition and the period of impediment to school attendance must arise from a precise medical certificate issued by the hospital in which the student was admitted. The medical certification, then, is the prerequisite to be able to get the education at home. It' should make the distinction between disability and home schooling.

The law of February 5, 1992 No 104 which governs the rights of the child with disabilities, provides that a disabled pupil is guaranteed and adequate support to the family through the allocation of specialist teachers and assistants in order to achieve the autonomy and the social integration. This support can be in the form of personal or family support services, but can also be understood as a psychological, psycho-pedagogic and technical.The school is an educational community in a context that is contrary to the multi-hospital or home environments where the intervention must be limited in time. The teacher does not have the class but is he and the student who, at that time, has special needs: the disease that the returns on his person at the time It' essential that the teacher knows how to master the tools and instructional models customized and active; know also compete with 
more parties involved in the educational relationship; knows how to communicate with their families, if present, the pupil in question. The key points of the teacher in Hospital and Home Care in Education are: teaching flexible and attractive; essential content and targeted selection of needs, individualized instruction and personalized educational dialogue is always open and clear; methods that foster the prominence of the pupil connection with the health care world and its activities; intelligent use of technology and connecting with outside world. The skills of the teacher hospital and/or at home are:

Interpersonal skills. The teacher works in a border zone between attention to health and that the size of psychoeducation, which must be able to manage and build supporting the mental load that the situation requires;

Organizational skills. The organization requires constant flexibility, ability to cope with the new, the unexpected and the finalization of the intervention at the same time teaching the process of educational development of the individual;

Teaching skill The teacher must know how to invent learning paths;

Institutional Responsibilities. The teacher should have the awareness of the importance of the discipline and its relationship with other disciplines, the organization and functioning of the education system, roles and responsibilities within the school and the relationship with the outside world. It passes through the knowledge of programmatic indications, documents Ministerial and Presidential Decree 122/2009 on the assessment that recognizes the value of Education and to lend Education at Home and in Hospital.

The commitment of all those who work for the realization of education in hospital and residence is in the direction of further action training of teachers; accompany and support a model training and education focused on the person and his needs, collaborate with the family to draw up the POF which takes account of the needs of the pupil and the environment
In the hospital a sick child must obviously find a competent person who is able to cure him and this is the first purpose of a pediatric ward which must recognize the specificity of childhood which means recognizing the child as a whole, healthy and sick at the same time. If the lanes are able to assign the spaces reserved to play and study, we welcome the young patients while respecting their being [3].

As rightly writes Canevaro [9] the young patients are forced to live in a "forest" full of strange machinery and masked people, who do not know. For the first time in their lives have to be away from home, without understanding in depth the reason. The school is the meeting point of all the "lost children" in that environment that acquire the essential tools to return home at last, to get out of the "woods" without fear, but with a new force that will inspire them to return to the lives of more serene and more grown up.

\section{References}

[1] Fantone, G., Initiatives for the improving of chronically ill and / or hospitalized children's quality of life, in Ponzella A., Pierucci I., Di Vita G. (by), "The child's pain: we can and we must fight", Day of retraining, Sapri (SA), 27-05-2000, pp. 52-55.

[2] Kanizsa S., Luciano E., The hospital school, Carocci, Roma, 2006.

[3] Capurso M., Play and study in the hospital, Erickson Edizioni, Trento, 2001, 89.

[4] Iodice F., The point of view of the school, AA.VV., The school outside the school: the school hospital in the European context, International Seminar of study and production, Acts and Documents, Castel San Pietro Terme (BO), 1-3-03- 2001, 16-19.

[5] Cipollone, A., The child and the school in the hospital, "Life of the Child”, n. 51, 2002, 17-19.

[6] Capurso M., Trappa, M. The house bites. The fear of the hospital in the imagination of the child, Edizioni Magi, Roma, 2005.

[7] Benini E., Children in pajamas, Edizioni Magi, Roma, 2004.

[8] Lemineur C., The French experience of hospital school, AA.VV., The school outside the school: the school hospital in the European context, International Seminar of study and production, Acts and Documents, Castel San Pietro Terme (BO), 1-3-03- 2001, 44-45.

[9] Canevaro A., Children who are lost in the woods. Identity and language of childhood, La Nuova Italia, Firenze, 1999. 